\title{
High survivorship of highly cross-linked polyethylene in revision Total hip Arthroplasty: a minimum 10-year follow-up study
}

\author{
Seung-Jae Lim', Ingwon Yeo ${ }^{\dagger}$, Chan-Woo Park ${ }^{1}$, Kyung-Jae Lee², Byung-Woo Min² and Youn-Soo Park ${ }^{1 *}$ (D)
}

\begin{abstract}
Purpose: Highly cross-linked polyethylene has been introduced to decrease osteolysis secondary to polyethylene wear debris generation. However, few long-term data on revision total hip arthroplasty (THA) using highly crosslinked polyethylene liners are available. The objective of this study was to determine long-term outcomes of a highly cross-linked polyethylene liner in revision THA.
\end{abstract}

Materials \& methods: We evaluated 63 revision THAs performed in 63 patients using a highly cross-linked polyethylene liner between April 2000 and February 2005. Of these, nine died and four were lost to follow-up. Thus, the final study cohort consisted of 50 patients (50 hips), including 26 males and 24 females with a mean age of 53 years (range, 27-75 years). Mean follow-up was 11 years (range, 10-14 years).

Results: The mean Harris hip score improved from 44 points preoperatively to 85 points at the final follow-up. No radiographic evidence of osteolysis was found in any hip. The mean rate of polyethylene liner wear was 0.029 $\mathrm{mm} /$ year (range, 0.003 to $0.098 \mathrm{~mm} /$ year). A total of 5 hips (10\%) required re-revision arthroplasty, including one cup loosening, one recurrent dislocation, and three deep infections. Kaplan-Meier survivorship with an end point of re-revision for any reason was $91.1 \%$ and for aseptic cup loosening was $97.9 \%$ at 11 years.

Conclusion: At a minimum of 10 years, the highly cross-linked polyethylene liners showed excellent clinical performance and implant survivorship, and were not associated with osteolysis in our patients with revision THAs.

Keywords: Revision total hip arthroplasty, Highly cross-linked polyethylene liner, Outcome

\section{Introduction}

The clinical outcomes of revision total hip arthroplasty are often inferior to those obtained with primary total hip arthroplasty (THA) [1]. Due to increasing numbers of patients undergoing THA and revision THA, improving the longevity of implant is highly desirable. Aseptic loosening has been known as the most frequent cause of revision after THA, even after revision THA [2, 3]. Aseptic loosening is associated with polyethylene wear debris that can stimulate an adverse local host response,

\footnotetext{
* Correspondence: ysp3504@skku.edu

tSeung-Jae Lim and Ingwon Yeo contributed equally to this work.

${ }^{1}$ Department of Orthopedic Surgery, Samsung Medical Center,

Sungkyunkwan University School of Medicine, 81 Irwon-ro, Gangnam-gu,

Seoul 06351, South Korea

Full list of author information is available at the end of the article
}

resulting in bone resorption and aseptic loosening of the prosthesis [4].

Highly cross-linked polyethylene (HXLPE) materials are developed specifically to reduce polyethylene wear and subsequent wear debris-induced osteolysis. Previous studies have clearly shown that HXLPE liners in primary THA have superior in vitro $[5,6]$ wear rates and midterm to long-term in vivo [7-9] wear rates. Recently, Feng et al. [10] have shown excellent clinical results of cementless THAs using HXLPE liner with a mean 12.9year postoperative follow-up (range, 7-18 years), demonstrating the potential benefits of this new material in providing longevity even to revision settings. The potentially important difference at revision surgery may be the increased possibility of third-body wear. Hip simulator 
wear tests have shown the superior wear behavior of HXLPE compared with non-HXLPE when aluminum oxide particles (for the simulation of ceramic particles) or bone cement, containing barium sulfate, were added to the wear test as third-body wear particles while articulating against $28-\mathrm{mm}$ cobalt-chromium $(\mathrm{CoCr})$ alloy femoral heads [11]. The improved wear performance of HXLPE over non-HXLPE suggests that HXLPE may perform well in a third-body abrasive wear environment [12]. However, the long-term clinical results of HXLPE liner in revision THA are not well known because it is difficult to study a large cohort of patients with substantial clinically-rich information. We have been performing revision THAs routinely using electron beam-irradiated and melted HXLPE (Longevity; Zimmer, Warsaw, IN, USA) as an articulating liner with titanium acetabular cup to assure good performance even in revision settings.

Therefore, we performed this study with 2 objectives. The first objective was to determine the clinical and radiographic results of patients who underwent revision THA using HXLPE liner at a minimum follow up of 10 years. The second objective was to determine the linear and volumetric wear rate of HXLPE in these hips.

\section{Materials and methods}

The study protocol was approved by the Institutional Review Board. We reviewed the records of a consecutive series of patients with revision THA who had their hips replaced using HXLPE liners. We retrospectively evaluated 63 revision THAs performed in 63 patients using Longevity HXLPE liners between April 2000 and February 2005. Of these patients, 9 died and 4 were lost to follow-up before the end of the 10-year evaluation. Thus, the final study cohort consisted of 50 patients (50 hips), including 26 males and 24 females with a mean age of 53 years (range, 27-75 years) at time of revision THA. Their mean body mass index was $23 \mathrm{~kg} / \mathrm{m}^{2}$ (range, $17-$ $35 \mathrm{~kg} / \mathrm{m}^{2}$ ). The study cohort of HXLPE liners was primarily revised for aseptic loosening (37 of 50 [74\%]), infected hip arthroplasty (7 of 50 [14\%]), and polyethylene wear and osteolysis (6 of 50 [12\%]). Of the total 50 hips used for this study, 32 (64\%) were performed for isolated cup revision, 12 (24\%) for simultaneous cup and stem revision, 5 (10\%) for liner cementing, and 1 (2\%) for isolated liner change. All infection-related causes were treated with 2-stage revision arthroplasty. The mean duration of follow-up was 11 years (range, 10-14 years). A summary of the demographic data is provided in Table 1.

\section{Prosthesis}

All surgeries were performed at a single institution by a single experienced surgeon. The Longevity HXLPE liner
Table 1 Demographic data

\begin{tabular}{ll}
\hline Number of patients (hips) & $50(50)$ \\
Age at revision surgery (years) & $53(27-75)$ \\
Gender (Male:Female) & $26: 24$ \\
Body-mass index $\left(\mathrm{kg} / \mathrm{m}^{2}\right)$ & $23(17-35)$ \\
Cause of revision surgery (\%) & \\
$\quad$ Aseptic loosening & $37(74)$ \\
$\quad$ Infection & $7(14)$ \\
$\quad$ Polyethylene wear and osteolysis & $6(12)$ \\
Duration of follow-up (years) & $11(10-14)$ \\
Values are presented as mean (range). & \\
\hline
\end{tabular}

was used in all hips. Uncemented cups and uncemented stems were used in all hips. Cementless titanium acetabular cups (Trilogy Acetabular Hip System; Zimmer) were press-fitted (1-2 mm) with 1 or 2 screws used for supplemental fixation. The femoral head size was selected to maintain a polyethylene thickness of approximately 6 $\mathrm{mm}$ to avoid problems associated with thin polyethylene, particularly at the rim of the acetabulum. Average thickness of polyethylene was $8.9 \mathrm{~mm}$ (range, $6.1-14.3 \mathrm{~mm}$ ). It was calculated using Zimmer's Longevity product brochure [13]. A cobalt-chromium femoral head was used in 36 hips ( $28 \mathrm{~mm}$ head in 33 hips and $22 \mathrm{~mm}$ in 3 hips). A 3rd-generation alumina ceramic femoral head was used in 14 hips ( $28 \mathrm{~mm}$ in 14 hips). Although the decision for use of a cobalt-chromium or ceramic head was at the operating surgeon's discretion, a ceramic head was not used in situations of damaged stem tapers. As mentioned above, femoral component was replaced simultaneously for 12 hips.

\section{Evaluation}

Each patient was clinically and radiographically assessed 4 weeks, 3 months, 6 months, 12 months after surgery, and annually thereafter. Clinical outcomes were assessed using a physical examination and Harris hip score (HHS) [14] at each follow-up interval. Standard radiographs included anteroposterior (AP) and translateral view of the hip. Radiographs taken 4 weeks after the index operation served as the baseline for all subsequent comparisons. These radiographs were analyzed for wear, radiolucent lines, osteolysis, or a change in the position of the component over time. Wear of HXLPE was measured using Polywear technique [15]. Radiographs were evaluated for loosening (defined as a change in component position of greater than 5 $\mathrm{mm}$ or a circumferential radiolucent line of $2 \mathrm{~mm}$ or greater) [16]. Acetabulum and femur were evaluated for evidence of osteolysis (defined as a nonlinear radiolucency greater than $5 \mathrm{~mm}$ of the bone adjacent to the prosthesis). Findings were recorded for 3 zones of the acetabulum described by DeLee and Charnley [17] and 7 zones of the 
femur described by Gruen et al. [18]. The position of the acetabular component was determined according to the method of Woo and Morrey [19]. Abduction was measured on the AP pelvic radiograph as the angle formed by lines drawn tangential to the acetabular component and tangential to the horizontal line joining the teardrop. Anteversion was measured on the true lateral radiograph as the angle formed by a line drawn tangential to the face of the acetabular component and a line drawn perpendicular to the horizontal plane. Femoral component stability and osseointegration were assessed using method described by Engh et al. [20].

Polyethylene wear was determined from annual radiographs using computer-assisted method with PolyWare software (Draftware Developers, Vevay, IN) [21]. This software can read tagged image file format (TIFF) files digitized from radiographs. It can identify the center of the femoral head and acetabular shell from the detected edges automatically. In addition, it can calculate the linear wear by distance between two points. All radiographs were measured by the same observer. To reduce disproportionate effects of embedding and creep, the initial radiograph used was the one taken 6 months after surgery [22]. Every Xray picture was measured 5 times. After excluding the highest and lowest value, the mean value of the remaining 3 results was calculated. Intra-observer reliability was determined using PRO Mixed procedure of SAS program (Information Technology Services; Austin, TX, USA). The intra-observer error was within $0.025 \mathrm{~mm}$. The end point of this study was the first re-revision THA (for aseptic or septic reasons). Re-revision was defined as any operation in which a previously implanted component was replaced.

\section{Statistical analysis}

All statistical analyses were performed using PASW Statistics version 23.0 (IBM Corp., Armonk, NY). Student's $t$-test was used to compare preoperative and postoperative HHS. The polyethylene wear data of the $\mathrm{CoCr}$ and ceramic femoral head groups were compared with use of the Mann-Whitney U test. Kaplan-Meier survivorship analysis was performed for all hips, with re-revision of either component as an end point. Statistical significance was considered when $P$ value was less than 0.05 .

\section{Results}

\section{Clinical outcomes}

The mean HHS significantly $(P<0.001)$ improved from 44 points (range, 24-89) preoperatively to 85 points (range, 52-100) at the final follow-up. No patient required any kind of walking support at the time of the latest follow-up.

\section{Radiographic results}

The average abduction angle and anteversion of the acetabular component were $41.2^{\circ}$ (range, $43^{\circ}$ to $56^{\circ}$ ) and $14.7^{\circ}$ (range, $8^{\circ}$ to $23^{\circ}$ ), respectively. All acetabular components were fixed by bony ingrowth except 1 hip, for which the cup was replaced due to aseptic loosening (Fig. 1). Three hips (6.0\%) had radiolucent lines around the acetabular component without the evidence of component loosening. At the femoral side, the radiolucent lines were found in 5 hips (10.0\%) in zones 1 and 7 , however, they did not progress during the observation period. No hips had $>5 \mathrm{~mm}$ of subsidence of the femoral stem.
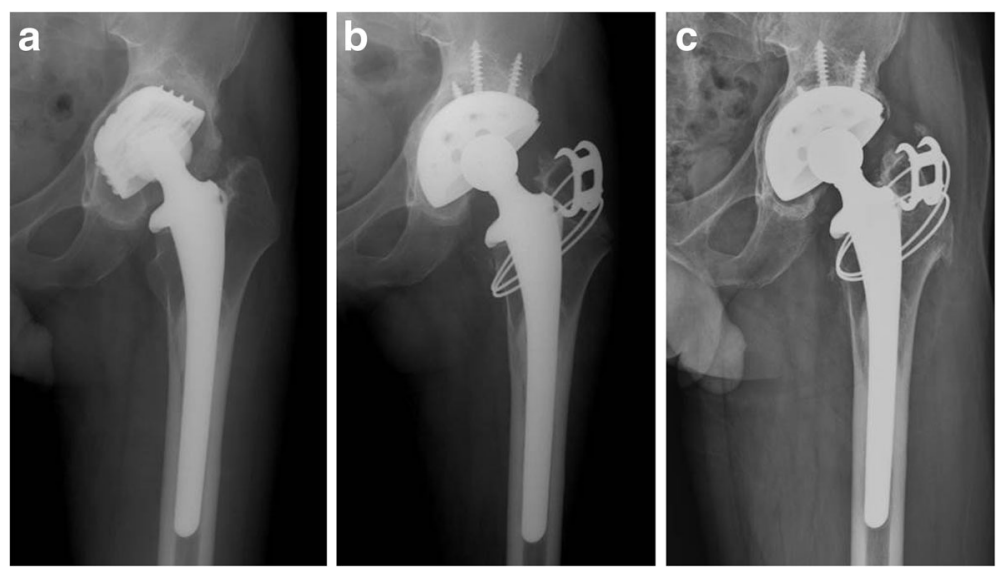

Fig. 1 (a) Preoperative radiograph showing aseptic loosening of acetabular cup; (b) Postoperative radiograph of cementless total hip arthroplasty performed with Longevity higly cross-linked polyethylene liner and 28-mm metal head; (c) Twelve-year follow-up radiograph showing well-fixed prostheses without osteolysis. The polyethylene liner wear rate was $0.014 \mathrm{~mm} /$ year 


\section{Condition of wear}

The mean rate of polyethylene liner wear was $0.029 \mathrm{~mm} /$ year (range, 0.003 to $0.098 \mathrm{~mm} /$ year). With the numbers available, there was no significant difference between the $\mathrm{CoCr}$ and ceramic femoral head groups with regard to the rate of polyethylene liner wear $(P=0.751)$. At the final follow-up, no hip was an outlier based on the threshold of osteolysis at $0.10 \mathrm{~mm}$ per year $[23,24]$ because all liners had wear rates below this level.

\section{Re-revision and survivorship}

During the follow-up period, 5 (10\%) hips required rerevision arthroplasty. One hip required re-revision surgery due to aseptic acetabular cup loosening at 6.5 years postoperatively. One required re-revision with a constrained liner due to recurrent dislocations. Three sustained deep infections required additional surgical procedures. However, none of the liners was revised due to polyethylene wear or mechanical failure of the polyethylene. The characteristics of patients who were re-revised are summarized in Table 2 . The Kaplan-Meier survivorship with an end point of re-revision for any reason was $91.1 \%$ (95\% confidence interval [CI], 86.7 to $100 \%$ ) at 11 years. For aseptic cup loosening, the KaplanMeier survivorship was $97.9 \%$ (Fig. 2).

\section{Complications}

There was no evidence of intraoperative periprosthetic fractures or intraoperative acetabular loosening. No case of sciatic nerve palsy, symptomatic venous thromboembolism, or surgery-related mortality was observed. However, during the follow-up period, there were 2 cases of postoperative periprosthetic fractures (1 acetabular fracture and 1 femoral fracture) associated with high-energy trauma. These fractures healed after open reduction and internal fixation.

\section{Discussion}

Aseptic loosening and osteolysis are the most common causes of revision surgery following THA after a long term $[2,3]$. One approach to reduce aseptic loosening and osteolysis was to modify the material properties of bearing surfaces [25, 26]. HXLPE liners have been developed with improved resistance to wear and fewer wear particles generated in vitro $[5,6]$. Several authors have studied the durability of HXLPE bearings in hip arthroplasty and reported favorable radiographic and clinical outcomes of HXLPE bearings in primary settings [7-10]. Our previous study has also found that HXLPE bearings used in young patients with osteonecrosis of femoral head are less likely to be replaced for extensive wear and osteolysis than conventional polyethylene bearings in revision settings [27]. The potentially important difference at revision surgery may be the increased possibility of third-body wear. Hip simulator wear tests have shown the superior wear behavior of HXLPE compared with non-HXLPE in a third-body abrasive wear environment $[11,12]$. However, the long-term clinical results of HXLE liner in revision THA are not well known.

The first objective of this study was to determine the clinical and radiographic outcomes of cementless revision THA using current techniques and HXLPE bearings with a minimum follow-up of 10 years. In our study, Kaplan-Meier survivorship with an end point of rerevision for any reason was $91.1 \%$ (95\% CI: 86.7 to $100 \%$ ) at 11 years. We found these types of bearings had good mid- to long-term follow-up results. This has not been previously reported in revision settings. Implant survivorship in our study is comparable to that of primary THA. A recent large population-based study has shown that cumulative incidence for any revision is $5.3 \%$ for metal on PE in primary THA after follow-up of 8.3 years [28]. Monti et al. [29] recently reported that the age was the only patient-associated risk factor for re-

Table 2 Characteristics of patients with re-revision for reasons other than periprosthetic fracture

\begin{tabular}{|c|c|c|c|c|c|c|c|c|c|c|c|c|}
\hline $\begin{array}{l}\text { Patient } \\
\text { no. }\end{array}$ & Sex & $\begin{array}{l}\text { Age at } \\
\text { revision }\end{array}$ & $\begin{array}{l}\text { Reason } \\
\text { for revision }\end{array}$ & $\begin{array}{l}\text { Method } \\
\text { of revision }\end{array}$ & $\begin{array}{l}\text { Acetabular } \\
\text { cup at } \\
\text { revision } \\
\text { (size) }\end{array}$ & $\begin{array}{l}\text { Acetabular } \\
\text { liner at } \\
\text { revision } \\
\text { (thickness) }\end{array}$ & $\begin{array}{l}\text { Femoral } \\
\text { head at } \\
\text { revision } \\
\text { (size) }\end{array}$ & $\begin{array}{l}\text { Acetabular } \\
\text { cup inclination } \\
\text { at revision }\left({ }^{\circ}\right)\end{array}$ & $\begin{array}{l}\text { Acetabular } \\
\text { cup } \\
\text { abduction } \\
\text { at revision }\left({ }^{\circ}\right)\end{array}$ & $\begin{array}{l}\text { Months } \\
\text { from } \\
\text { revision } \\
\text { to re-revision }\end{array}$ & $\begin{array}{l}\text { Reason for } \\
\text { re-revison }\end{array}$ & $\begin{array}{l}\text { Method of } \\
\text { re-revision }\end{array}$ \\
\hline 1 & M & 43 & $\begin{array}{l}\text { Aseptic } \\
\text { loosening }\end{array}$ & $\begin{array}{l}\text { Cup } \\
\text { revision }\end{array}$ & $\begin{array}{l}\text { Trilogy } \\
(66 \text { mm) }\end{array}$ & $\begin{array}{l}\text { Longevity } \\
(13.3 \mathrm{~mm})\end{array}$ & $\begin{array}{l}\text { Metal } \\
(28 \mathrm{~mm})\end{array}$ & 38.3 & 9.3 & 80 & $\begin{array}{l}\text { Aseptic } \\
\text { loosening }\end{array}$ & Cup revision \\
\hline 2 & F & 65 & $\begin{array}{l}\text { Aseptic } \\
\text { loosening }\end{array}$ & $\begin{array}{l}\text { Cup \& } \\
\text { stem } \\
\text { revision }\end{array}$ & $\begin{array}{l}\text { Trilogy } \\
\text { (48 mm) }\end{array}$ & $\begin{array}{l}\text { Longevity } \\
(6.2 \mathrm{~mm})\end{array}$ & $\begin{array}{l}\text { Ceramic } \\
(28 \mathrm{~mm})\end{array}$ & 44.0 & 12.5 & 6 & $\begin{array}{l}\text { Recurrent } \\
\text { dislocation }\end{array}$ & Cup revision \\
\hline 3 & F & 62 & $\begin{array}{l}\text { Aseptic } \\
\text { loosening }\end{array}$ & $\begin{array}{l}\text { Cup } \\
\text { revision }\end{array}$ & $\begin{array}{l}\text { Trilogy } \\
\text { (48 mm) }\end{array}$ & $\begin{array}{l}\text { Longevity } \\
(6.2 \mathrm{~mm})\end{array}$ & $\begin{array}{l}\text { Metal } \\
(28 \mathrm{~mm})\end{array}$ & 38.0 & 10.5 & 78 & Infection & $\begin{array}{l}2 \text { stage cup \& } \\
\text { stem re- } \\
\text { revision }\end{array}$ \\
\hline 4 & M & 75 & Infection & $\begin{array}{l}\text { Cup \& } \\
\text { stem } \\
\text { revision }\end{array}$ & $\begin{array}{l}\text { Trilogy } \\
(64 \text { mm) }\end{array}$ & $\begin{array}{l}\text { Longevity } \\
(12.3 \mathrm{~mm})\end{array}$ & $\begin{array}{l}\text { Ceramic } \\
(28 \mathrm{~mm})\end{array}$ & 36.4 & 8.5 & 1 & Infection & $\begin{array}{l}\text { Resection } \\
\text { arthroplasty }\end{array}$ \\
\hline 5 & M & 56 & $\begin{array}{l}\text { Aseptic } \\
\text { loosening }\end{array}$ & $\begin{array}{l}\text { Cup } \\
\text { revision }\end{array}$ & $\begin{array}{l}\text { Trilogy } \\
(56 \mathrm{~mm})\end{array}$ & $\begin{array}{l}\text { Longevity } \\
(8.3 \mathrm{~mm})\end{array}$ & $\begin{array}{l}\text { Metal } \\
(28 \mathrm{~mm})\end{array}$ & 49.1 & 13.0 & 50 & Infection & $\begin{array}{l}2 \text { stage cup } \\
\text { re-revision }\end{array}$ \\
\hline
\end{tabular}



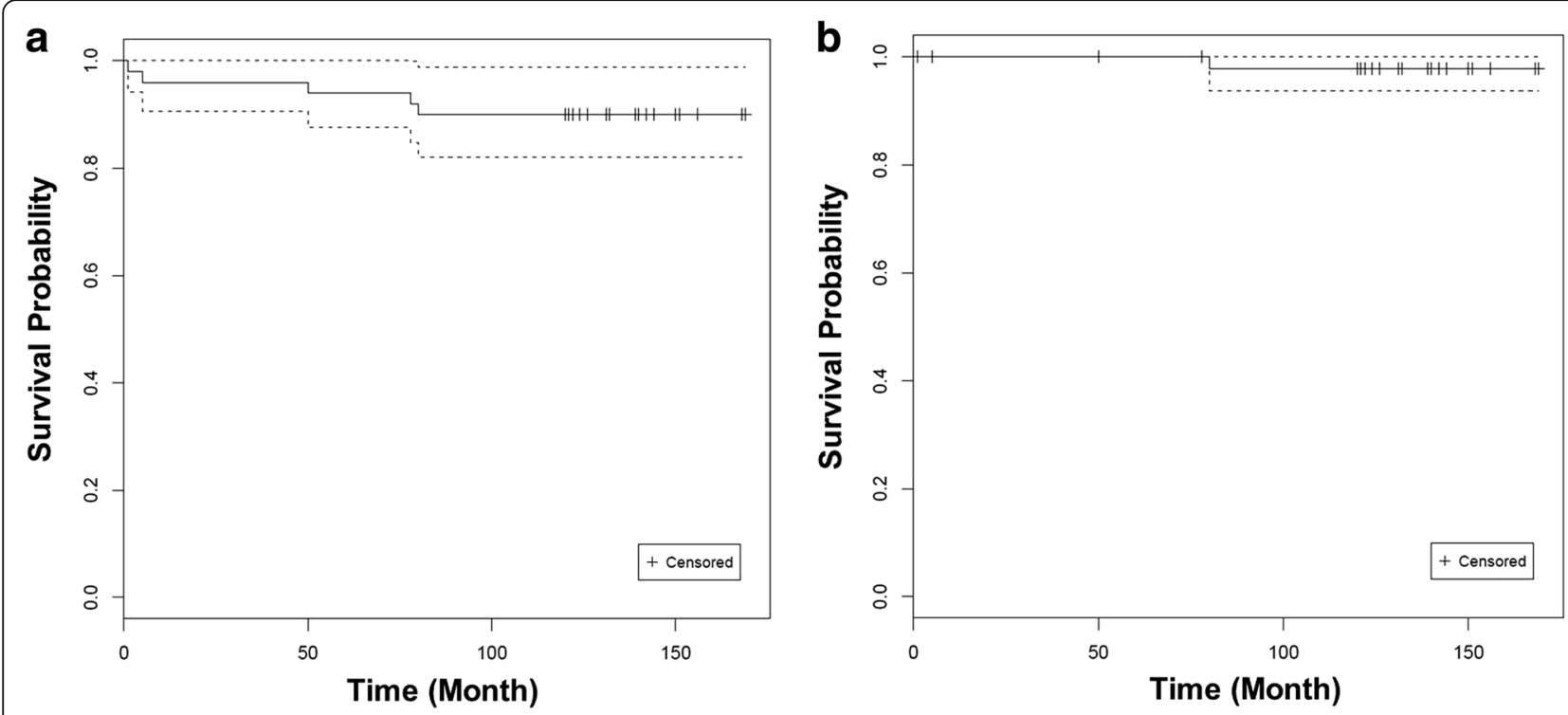

Fig. 2 Kaplan-Meier survival analysis of revision THAs using HXLPE liner. (a) Survival with re-revision for any reason as the end point; (b) Survival with re-revision for aseptic loosening as the end point. Dotted lines indicating 95\% confidence interval

revision THA. According to that study, for every tenyear increase in patient's age, the hazard for re-revision is significantly $(P=0.004)$ decreased by a factor of 0.72 ( $95 \% \mathrm{CI}, 0.58$ to 0.90$)$. The mean age at revision surgery was 53 years in this study. Considering the relatively younger age of these patients at revision surgery, our implant survival rate was excellent. HHS, the most commonly used scoring method, significantly improved postoperatively, with a mean of 85 (80-90 constitutes a "good outcome") at the final follow-up.

The second purpose of this study was to determine the linear and volumetric wear rate of HXLPE in revision THA using HXLPE bearings at a minimum followup of 10 years. Our results revealed that the mean rate of polyethylene liner wear was $0.029 \mathrm{~mm} /$ year (range, 0.003 to $0.098 \mathrm{~mm} /$ year), comparable to that of HXLPE in primary THA. Reynolds et al. [30] have conducted a comparison study for all current wear rate of HXLPE in primary THA and found that the range is from 0.002 to $0.15 \mathrm{~mm} / \mathrm{yr}$. We used AP hip radiographs to measure polyethylene wear rate. The beam is centered over the hip, which may be more orthogonal to the vector of penetration. Nimrod et al. [31] found a significant difference in measurements of linear penetration when comparing AP pelvis to hip radiographs. Lower rates are found to be recorded when AP pelvis is used. Therefore, our result has less chance to underestimate the amount of penetration. The excellent clinical and radiographic results of HXLPE liners suggested that free radicals and oxidation do not appear to accelerate annealed HXLPE liner wear rate during this time period. Through the current study on HXLPE liners with a minimum follow- up of 10 years, we found that these types of bearings had reliable mechanical properties even in mid- to long-term situations. This has not been previously reported in revision settings.

There are several possible reasons for the success of our revision THAs other than HXLPE liners itself. It has been suggested that reduced strength and toughness of HXLPE may play an important role in the fracture of liner rims and the locking mechanisms $[32,33]$. These altered mechanical properties of HXLPE can be adversely affected by acetabular inclination, polyethylene thinness, or both. The mean inclination angle of acetabular cup and mean thickness of HXLPE liners in this study were 41.2 and $8.9 \mathrm{~mm}$, respectively. These inclination angle and thickness of liner were in acceptable ranges according to recent studies, which might have prevented unnecessary rerevision surgeries. We performed all revision THA using uncemented stems. Fixation type and the risk of re-revision have been studied extensively. Multiple contemporary studies have reported highly successful outcomes of revision THAs using uncemented stems $[34,35]$. In addition, the operator had been performing more than 50 revision THAs annually in our institution. Some authors have also suggested that increased experience of surgeon can improve the outcome of technically challenging hip arthroplasty. Khatod et al. [29] have reported that the hazard of re-revision THA is significantly $(P=0.049)$ decreased by a factor of 0.93 (95\% CI: 0.86 to 0.99 ) for every 5unit increase in the number of revision arthroplasties performed by the surgeon. 
Many authors have also paid attention to materials of femoral head and searched for ideal pairings of acetabular liner and femoral head in hip arthroplasty. For an existing taper during revision surgery, it is generally not recommended to use a ceramic head because undetected damage in the taper may increase the risk of ceramic fracture [36-38]. In addition, a component mismatch may lead to accelerated wear and earlier revision [39]. In our patients, 36 hips received $\mathrm{CoCr}$ femoral head and HXLPE liner while 14 hips received ceramic femoral head and HXLPE liner. A recent multicenter randomized controlled trial on polyethylene wear rate showed that no significant $(P=0.153)$ difference was noted between $\mathrm{CoCr}$ and ceramic head when articulating with HXLPE [40]. Based on this trial, it appears that using a HXLPE acetabular liner is more important in reducing THA component wear than the choice of femoral head bearing with mid-term follow-up time. Therefore, we did not pay attention to the difference between the two materials of femoral head.

This study had several limitations, including its retrospective nature. In addition, this was not a comparative study. Therefore, conclusions cannot be drawn about the outcomes of HXLPE liner compared to ceramic liner. Moreover, we had a relatively small number of patients compared to studies on primary THA with a large number of patients. However, only a small cohort of patients was available for observation due to the unique usage of this bearing system for revision THA. Furthermore, no long-term data are available at this point. In addition, only one experienced adult reconstruction surgeon from a single high-volume center performed all these revisions. Thus, the outcomes may not be generalized to other centers with lower volumes. The technique used to evaluate our patients' polyethylene wear is also a possible limitation because alternative methods can be used to measure wear [41].

\section{Conclusions}

At a minimum of 10 years follow-up, our results revealed that the use of HXLPE liner in revision settings was promising even in a cohort of our patients with a mean age of 53 years. Patients' clinical scores were improved. From a radiological point of view, only one aseptic acetabular loosening took place after a minimum of 10 years after implantation. Based on the encouraging outcomes in this challenging revision THA, we believe that cementless THA using HXLPE liner is a promising procedure. Due to the intermediate follow-up time and the relatively small study group in a highly specialized institution, these results may not be extrapolated to the general population. Further evaluation for this patient group after a longer follow-up time is needed in the future.

\section{Abbreviations}

THA: total hip arthroplasty; HXLPE: highly cross-linked polyethylene; CoCr: cobalt-chromium; HHS: Harris hip score; AP: anteroposterior

\section{Acknowledgements \\ None.}

\section{Authors' contributions}

SJL conceptualized the research and was a major contributor in writing the manuscript. IY interpreted the patient data and was a major contributor in writing the manuscript. CWP collected and analysed the patient data. KL and BWM analysed the data regarding annual polyethylene wear rate. YSP supervised the study and reviewed the manuscript. All authors read and approved the final manuscript.

\section{Funding}

This research did not receive any specific grant from funding agencies in the public, commercial, or not-for-profit sectors.

\section{Availability of data and materials}

The datasets used and/or analysed during the current study are available from the corresponding author on reasonable request.

\section{Ethics approval and consent to participate}

Informed consent was obtained from all participants included in the study.

\section{Conflict of interest}

Youn-Soo Park is a paid consultant for DePuy Synthes.

\section{Consent for publication \\ A consent to publish radiographic images was obtained from the corresponding patient.}

\section{Author details}

'Department of Orthopedic Surgery, Samsung Medical Center, Sungkyunkwan University School of Medicine, 81 Irwon-ro, Gangnam-gu, Seoul 06351, South Korea. ${ }^{2}$ Department of Orthopaedic Surgery, Dongsan Medical Center, Keimyung University School of Medicine, Daegu, South Korea.

Received: 19 June 2019 Accepted: 13 November 2019

Published online: 17 December 2019

\section{References}

1. Lie SA, Havelin LI, Furnes ON, Engesaeter LB, Vollset SE. Failure rates for 4762 revision total hip arthroplasties in the Norwegian Arthroplasty register. J Bone Joint Surg Br. 2004:86(4):504-9.

2. Bozic KJ, Kamath AF, Ong K, et al. Comparative epidemiology of revision Arthroplasty: failed THA poses greater clinical and economic burdens than failed TKA. Clin Orthop Relat Res. 2015;473(6):2131-8.

3. Haynes JA, Stambough JB, Sassoon AA, Johnson SR, Clohisy JC, Nunley RM. Contemporary surgical indications and referral trends in revision Total hip Arthroplasty: a 10-year review. J Arthroplast. 2016;31(3):622-5.

4. Jacobs JJ, Shanbhag A, Glant TT, Black J, Galante JO. Wear debris in total joint replacements. J Am Acad Orthop Surg. 1994;2(4):212-20.

5. Rieker CB, Konrad R, Schön R, et al. In vivo and in vitro surface changes in a highly cross-linked polyethylene. J Arthroplast. 2003;18(7 Suppl 1):48-54.

6. Watanabe K, Kyomoto M, Saiga K, et al. Effects of surface modification and bulk geometry on the Biotribological behavior of cross-linked polyethylene: Wear testing and finite element analysis. Biomed Res Int. 2015;2015:435432.

7. Nakashima Y, Sato T, Yamamoto T, et al. Results at a minimum of 10 years of follow up for AMS and PerFix HA-coated cementless total hip arthroplasty: impact of cross linked polyethylene on implant longevity. J Orthop Sci. 2013;18(6):962-8.

8. Garvin KL, White TC, Dusad A, Hartman CW, Martell J. Low wear rates seen in THAs with highly crosslinked polyethylene at 9 to 14 years in patients younger than age 50 years. Clin Orthop Relat Res. 2015;473(12):3829-35.

9. So K, Goto K, Kuroda Y, Matsuda S. Minimum 10-year Wear analysis of highly cross-linked polyethylene in Cementless Total hip Arthroplasty. J Arthroplast. 2015;30(12):2224-6. 
10. Feng JE, Novikov D, Chen K, Kim K, Bookman J, Anoushiravani AA, Hamula M, Snir N, Schwarzkopf R. Up to 18-year follow-up Wear analysis of a firstgeneration highly cross-linked polyethylene in primary Total hip Arthroplasty. J Arthroplast. 2018;33(10):3325-8.

11. Bragdon CR, Jasty M, Muratoglu OK, O'Connor DO, Harris WH. Third-body wear of highly cross-linked polyethylene in a hip simulator. J Arthroplast. 2003;18(5):553-61.

12. O'Brien ST, Burnell CD, Hedden DR, Brandt JM. Abrasive wear and metallosis associated with cross-linked polyethylene in total hip arthroplasty. J Arthroplasty. 2013;28(1):197.e17-21.

13. Babovic N, Trousdale RT. Total hip arthroplasty using highly cross-linked polyethylene in patients younger than 50 years with minimum 10-year follow-up. J Arthroplast. 2013;28(5):815-7.

14. Harris WH. Traumatic arthritis of the hip after dislocation and acetabular fractures. Treatment by mold arthroplasty. An end-result study using a new method of result evaluation. J Bone Joint Surg Am. 1969;51(4):737-55.

15. Kraay MJ, Moore RD, Martell JM, Rimnac CM. Reassessment of computerized wear measurement for total hip arthroplasty with correction for projectional image distortion: a brief follow-up report. J Bone Joint Surg Am. 2010;92: 1858-67.

16. Massin P, Schmidt L, Engh CA. Evaluation of cementless acetabular component migration. An experimental study. J Arthroplasty. 1989;4:245-51.

17. DeLee JG, Charnley J. Radiological demarcation of cemented sockets in total hip replacement. Clin Orthop Relat Res. 1976;121:20-32.

18. Gruen TA, McNeice GM, Amstutz HC. 'Modes of failure' of cemented stemtype femoral components: a radiographic analysis of loosening. Clin Orthop Relat Res. 1979;141:17-27.

19. Woo RY, Morrey BF. Dislocations after total hip arthroplasty. J Bone Joint Surg Am. 1982;64:1295-306.

20. Engh CA, Massin P, Suthers KE. Roentgenographic assessment of the biologic fixation of porous-surfaced femoral component. Clin Orthop Relat Res. 1990;257:107-28.

21. Devane PA, Horne JG. Assessment of polyethylene wear in total hip replacement. Clin Orthop Relat Res. 1999;369:59-72.

22. Glyn-Jones S, McLardy-Smith P, Gill HS, et al. The creep and wear of highly cross linked polyethylene: a three-year randomised, controlled trial using radiostereometric analysis. J Bone Joint Surg Br. 2008;90:556-61.

23. Dowd JE, Sychterz CJ, Young AM, et al. Characterization of long-term femoral-head penetration rates. Association with and prediction of osteolysis. J Bone Joint Surg Am. 2000;82:1102-7.

24. Wan Z, Dorr LD. Natural history of femoral focal osteolysis with proximal ingrowth smooth stem implant. J Arthroplast. 1996;11:718-25.

25. Sundfeldt M, Carlsson LV, Johansson CB, Thomsen P, Gretzer C. Aseptic loosening, not only a question of wear: a review of different theories. Acta Orthop. 2006;77:177-97.

26. Bozic KJ, Kurtz S, Lau E, et al. The epidemiology of bearing surface usage in total hip arthroplasty in the United States. J Bone Joint Surg Am. 2009;91(7): 1614-20.

27. Park YS, Moon YW, Lee KH, Lim SJ. Revision hip arthroplasty in patients with a previous total hip replacement for osteonecrosis of the femoral head. Orthopedics. 2014;37(12):e1058-62.

28. Claus V, Alma BP, Per KA, Søren O. Comparison of the risk of revision in cementless total hip arthroplasty with ceramic-on-ceramic and metal-onpolyethylene bearings: data on 11,096 patients from the Danish Hip Arthroplasty registry. Acta Orthop. 2015:86(4):477-84

29. Khatod M, Cafri G, Inacio MC, Schepps AL, Paxton EW, Bini SA. Revision total hip arthoplasty: factors associated with re-revision surgery. J Bone Joint Surg Am. 2015;97(5):359-66.

30. Reynolds SE, Malkani AL, Ramakrishnan R, et al. Wear analysis of firstgeneration highly cross-linked polyethylene in primary total hip arthroplasty. J Arthroplast. 2012;27:1064-8

31. Snir N, Kaye ID, Klifto CS, Hamula MJ, Wolfson TS, Schwarzkopf R, Jaffe FF. 10year follow-up wear analysis of first-generation highly crosslinked polyethylene in primary total hip arthroplasty. J Arthroplast. 2014;29(3):630-3.

32. Tower SS, Currier JH, Currier BH, et al. Rim cracking of the cross-linked longevity polyethylene acetabular liner after total hip arthroplasty. J Bone Joint Surg Am. 2007:89:2212-7.

33. Baker DA, Hastings RS, Pruitt L. Study of fatigue resistance of chemical and radiation cross linked medical grade ultrahigh molecular weight polyethylene. J Biomed Mater Res. 1999;46:573-81.
34. Wirtz DC, Gravius S, Ascherl R, et al. Uncemented femoral revision arthroplasty using a modular tapered, fluted titanium stem: 5- to 16-year results of 163 cases. Acta Orthop. 2014;85(6):562-9.

35. Lachiewicz PF, Soileau ES. What is the survivorship of fully coated femoral components in revision hip arthroplasty? Clin Orthop Relat Res. 2015;473(2): 549-54.

36. Holmer P, Nielsen PT. Fracture of ceramic femoral heads in total hip arthroplasty. J Arthroplast. 1993;8:567-71.

37. Park YS, Hwang SK, Choy WS, Kim YS, Moon YW, Lim SJ. Ceramic failure after total hip arthroplasty with an alumina-on-alumina bearing. J Bone Joint Surg Am. 2006:88(4):780-7.

38. Hohman DW, Affonso J, Anders M. Ceramic-on-ceramic failure secondary to head-neck taper mismatch. Am J Orthop. 2011;40:571-3.

39. Allain J, Roudot-Thoraval F, Delecrin J, Anract P, Migaud H, Goutallier D. Revision total hip arthroplasty performed after fracture of a ceramic femoral head: a multicenter survivorship study. J Bone Joint Surg Am. 2003;85:825-30.

40. Jassim SS, Patel S, Wardle N, et al. Five-year comparison of wear using oxidised zirconium and cobalt-chrome femoral heads in total hip arthroplasty: a multicentre randomised controlled trial. Bone Joint J. 2015; 97-B(7):883-9.

41. Callary SA, Solomon LB, Holubowycz OT, Campbell DG, Munn Z, Howie DW. Wear of highly cross linked polyethylene acetabular components. Acta Orthop. 2015;86:159-68.

\section{Publisher's Note}

Springer Nature remains neutral with regard to jurisdictional claims in published maps and institutional affiliations.
Ready to submit your research? Choose BMC and benefit from:

- fast, convenient online submission

- thorough peer review by experienced researchers in your field

- rapid publication on acceptance

- support for research data, including large and complex data types

- gold Open Access which fosters wider collaboration and increased citations

- maximum visibility for your research: over $100 \mathrm{M}$ website views per year

At BMC, research is always in progress.

Learn more biomedcentral.com/submissions 